\title{
O ENSINO DA ESCRITA NO ENSINO FUNDAMENTAL: RELATO DE UMA EXPERIÊNCIA PEDAGÓGICA
}

\author{
Doris Regina Mieth Dal Magro* \\ Rita Maria Decarli Bottega**
}

\begin{abstract}
Resumo: Este trabalho analisa uma experiência pedagógica com a produção textual realizada com estudantes do Ensino Fundamental. O ensino da escrita nas escolas precisa ser significativo para que os alunos sejam estimulados continuamente a escrever e superar as suas dificuldades. Nesse processo de aprendizagem, a mediação pedagógica, mais do que corrigir, funciona como uma orientação para o estudante (re)organizar a sua produção. Para tanto entendemos a necessidade de se construir uma relação pedagógica colaborativa entre professor e aluno, alicerçada na pesquisa e na organização dos procedimentos didáticos adotados em sala de aula. A base teórica está pautada na concepção interacionista da linguagem.
\end{abstract}

Palavras-chave: Produção escrita. Ensino. Mediação Pedagógica.

\begin{abstract}
This study analyzes a pedagogical experience with a textual production carried out with Elementary School students. The teaching of writing in schools is important so that students are continually encouraged to write and overcome their difficulties. In this learning process, a pedagogical mediation, rather than correcting, it acts as a guide for the student (re) organize his/her production. Therefore, we understand the need to build a collaborative pedagogical relationship between teacher and student, based on the research and organization of didactic procedures adopted in the classroom. A theoretical basis is based on the interactionist conception of language.
\end{abstract}

Keywords: Written production. Teaching. Pedagogical Mediation.

\section{Introdução}

O trabalho com a produção escrita é um dos sustentáculos da disciplina de Português em todos os níveis de ensino. Aprende-se a escrever e aprimora-se esse registro ao longo de toda a vida escolar e acadêmica do indivíduo. Sob esse aspecto, a escrita é um processo, um contínuo de aprendizagem que pode ser melhorado com o passar do tempo.

Considerado o aspecto relevante da escrita na formação do sujeito para o exercício pleno dos papeis sociais, a escola deveria ser um local de excelência para os estudantes se tornarem habilidosos no trato com a palavra escrita ao concluírem a educação básica. Porém, o que percebemos é justamente o inverso e os exames nacionais como ENEM e vestibulares, de forma recorrente, demonstram esse fato. Nessa etapa, boa parte dos estudantes não consegue articular um texto de forma coerente, defender pontos de vista ou sequer narrar um fato corriqueiro.

Acreditamos que uma solução possível para reverter esse quadro seja trazer o estudante para o centro do trabalho pedagógico. Ajudá-lo a se responsabilizar pelo que escreve e a se posicionar em seu texto. Para tanto, apresentamos uma possibilidade de trabalho com a produção escrita que consideramos exitosa. Trazemos, de início, alguns postulados teóricos sobre o assunto para, na sequência, apresentarmos o relato da experiência realizada. Apresentamos, ainda, algumas proposições metodológicas que podem ser utilizadas para auxiliar os estudantes a superarem algumas das suas dificuldades.

\footnotetext{
* Mestranda do Mestrado Profissional em Letras-Profletras da Universidade Estadual do Oeste do ParanáUnioeste; dorisdalmagro@ hotmail.com.

** Professora Doutora em Educação do Mestrado Profissional em Letras na Universidade Estadual do Oeste do Paraná; professora do curso de gradução em Letras da Unioeste; ritabottega@uol.com.br.
} 


\section{Fundamentação teórica}

A questão da aquisição de uma escrita e de uma leitura proficientes por parte dos jovens estudantes precisaria ser encarada como prioridade por qualquer país que tenha, de fato, a intenção de desenvolvimento social pleno. Em um país como o Brasil, assolado por crises políticas, econômicas e éticas, é fundamental que os alunos saibam se expressar, contar de si e dos outros, numa constante interação social com o mundo o que torna o papel da escola fundamental, já que a "escrita é uma construção social, coletiva, tanto na história humana como na história de cada indivíduo. O aprendiz precisa das outras pessoas para começar e para continuar escrevendo" (GARCEZ, 2012, p.2). Normalmente, esse estímulo para o aprendiz escrever tem seu início nos bancos escolares e, nesse contexto, a mediação do professor é fundamental para que o estudante compreenda a importância e a gradação natural desse processo.

É preciso antes de tudo, compreender que todas as pessoas podem chegar a produzir bons textos, e que isso não é uma questão de ser "ungido" pelos deuses que escolhem os mais talentosos. É necessário também identificar bloqueios porventura construídos ao longo da vida escolar e eliminá-los (GARCEZ, 2012, p. 3).

Essa identificação dos bloqueios com relação à escrita pode ser tarefa do professor: algo difícil de se realizar, porém não impossível e extremamente necessário. Diríamos, ainda, que é tarefa de todos os professores de todas as disciplinas. Afinal, o aluno não escreve somente nas aulas de Língua Portuguesa. A produção de textos autônoma e consistente pode ser objetivo de todas as áreas do conhecimento, pois

Ler e escrever são tarefas da escola, questões para todas as áreas, uma vez que são habilidades indispensáveis para a formação de um estudante, que é responsabilidade da escola. Ensinar é dar condições ao aluno para que ele se aproprie do conhecimento historicamente construído e se insira nessa construção como produtor de conhecimento. Ensinar é ensinar a ler para que o aluno se torne capaz dessa apropriação, pois o conhecimento acumulado está escrito em livros, revistas, jornais, relatórios, arquivos. Ensinar é ensinar a escrever porque a reflexão sobre a produção de conhecimento se expressa por escrito. (GUEDES et al, 2011, p. 19, grifo nosso).

Dessa forma, todas as disciplinas podem acompanhar a apreensão dos conhecimentos específicos dos alunos por meio da produção escrita. Essa é uma alternativa que pode substituir as tradicionais avaliações que exigem apenas uma reprodução da fala do professor. Afinal, por meio da escrita fica evidenciado o que o aluno compreendeu e, a partir desse ponto, o professor pode (re)orientar seus procedimentos em sala.

Falamos em leitura e escrita porque são atividades complementares e todos os professores precisam assumir a responsabilidade de trabalhar com um aluno real, a partir do conhecimento que ele já possui para aquele que precisa ser efetivamente compreendido. Não há fórmulas prontas para isso. Há muito trabalho que precisa ser realizado da melhor forma possível para encontrar estratégias que possibilitem ultrapassar os limites e dificuldades impostos no cotidiano de sala de aula. Os professores são os profissionais que possuem conhecimento para lidar com os aspectos que envolvem o processo de ensino e sabem que os tempos de aprendizagem são diferentes entres os estudantes, precisam, além disso, levar em consideração que 
Ler e escrever são processos, frequentemente vistos como imagens espelhadas uma da outra, como reflexos sob ângulos opostos de um mesmo fenômeno: a comunicação através da língua escrita. Mas há diferenças fundamentais entre as habilidades e conhecimentos empregados na escrita, assim como há diferenças consideráveis entre os processos envolvidos na aprendizagem da escrita (SMITH apud SOARES, 1998, p. 68).

De forma que conhecer a maneira como os estudantes compreendem essas habilidades é importante para a execução do trabalho docente. Precisamos ter sempre em mente o fato de que todos os alunos devem ter acesso à leitura e à escrita em boas condições. Não obstante o seu comportamento e a sua história, eles merecem atenção e respeito quanto a suas vivências e expectativas. Nesse ponto, uma mediação pedagógica bem realizada e uma ação sistematizada da escola na construção de habilidades como a leitura e a escrita são indispensáveis para a inserção desses jovens numa vida efetivamente cidadã (NEVES et al, 2011, p. 16).

Esse compromisso não é fácil de ser realizado. Cada estudante é um sujeito social que traz para o ambiente escolar toda a sua experiência pessoal, tanto positiva, quanto negativa. A escola, muitas vezes, não consegue fazer frente às expectativas e necessidades desse aluno. E nesse contexto, torna-se muito difícil a relação de ensino-aprendizagem, uma vez que o estudante não consegue perceber a importância de escrever, de ler, entre outras tantas atividades que realiza na escola. $\mathrm{O}$ professor precisa ter muito discernimento no trato dessas singularidades para conseguir um mínimo de eficiência em suas aulas no que se refere à adesão do aluno para a compreensão da importância da leitura e da escrita.

Na realidade, o meio em que o ser humano vive e no qual se acham imerso é muito maior que seu ambiente físico e contorno imediato, já que está envolto também por sua história e pela sociedade que (o) criou e pelos seus discursos. A vivência cultural humana está sempre envolta em linguagem, e todos os nossos textos situam-se nessas vivências estabilizadas em gêneros. Nesse contexto, é central a ideia de que a língua é uma atividade sociointerativa de caráter cognitivo, sistemática e instauradora de ordens diversas na sociedade. $\mathrm{O}$ funcionamento de uma língua no dia-a-dia é, mais do que tudo, um processo de integração social. Claro que não é a língua que discrimina ou que age, mas nós que com ela agimos e produzimos sentidos (MARCUSCHI, 2008, P. 162-163).

De forma que, na escola, essa vivência cultural de cada sujeito interage com os outros e pode se constituir em material de trabalho para o professor: produzir sentidos a partir das experiências dos alunos, com a finalidade de aproximar o estudante do conhecimento e expandir os seus próprios limites. Essa integração entre professores e alunos, mediada pela linguagem, precisa ser muito mais do que atividades protocolares de leitura e produção textual. Podem produzir novos significados para que os estudantes compreendam o contexto social, cultural, econômico e ético em que estão inseridos e se reconheçam como sujeitos importantes nesses processos. Soares (1998, p. 46-47), em explicação sobre o termo letramento, afirma que muitas pessoas, apesar de alfabetizadas, não se envolvem com as práticas sociais da escrita. Esse fato provoca um distanciamento das pessoas sobre questões importantes e, com isso, tornam-se assujeitados, sem perspectivas, engajamentos ou opiniões que façam valer efetivamente o seu ponto de vista. Nessa perspectiva, no ensino, vemos estudantes que, por vezes, não conseguem articular suas opiniões de forma coerente e baseiam seus argumentos no senso comum. Portanto, ensinar o aluno a escrever e ser um 
sujeito de fato de seus posicionamentos, mais do que uma integração, é fator de emancipação social. Assim

\begin{abstract}
Para que a aprendizagem seja produzida, é indispensável o papel ativo e protagonista do aluno, que deve desenvolver uma atividade mental que possibilite a reelaboração de seus esquemas de conhecimento, processo na qual tem uma especial relevância o conflito cognitivo por meio do qual o aluno questiona suas ideias como passo prévio para a construção de significados (ZABALLA/ARNAU, 2010, p. 97).
\end{abstract}

Trazer o aluno para o centro da aprendizagem da escrita implica em possibilitar que o mesmo se desafie, entre em conflito com seus próprios paradigmas pré-estabelecidos, quebre suas expectativas e supere suas próprias limitações. Os alunos do ensino fundamental são leitores e produtores de textos em formação. Aos professores compete fazer o trabalho de andaimagem, auxiliando os aprendizes com conceitos desconhecidos, especificidades técnicas, com os recursos de linguagem que produzem variados sentidos, entre tantos outros requisitos que fazem significativos os anos letivos para os estudantes.

Ora, a escola e a educação básica são lugares sociais de ensinoaprendizagem de conhecimento acumulado pela humanidade - informações, indicações, regras, modelos -. Mas também, e fundamentalmente, de formação do sujeito social, de construção da ética e da moral, de circulação das ideologias. Falar na formação do leitor cidadão é justamente não olhar só uma das faces desta moeda; é permitir a nossos alunos a confiança na possibilidade e as capacidades necessárias ao exercício pleno da compreensão. Portanto, trata-se de nos acercarmos da palavra não de maneira autoritária, colada ao discurso do autor, para repeti-lo "de cór"; mas de maneira internamente persuasiva, isto é, podendo penetrar plasticamente, flexivelmente as palavras do autor, mesclar-nos a elas, fazendo de suas palavras nossas palavras, para adotá-las, contrariá-las, criticá-las, em permanente revisão e réplica (ROJO, 2002, p. 7, grifos da autora).

Em muitos casos, essa formação social do aluno, abordada pela autora, está totalmente centrada na escola. Muitas famílias, pelas mais diferentes razões, desistiram das suas responsabilidades. Assim, parte das crianças e adolescentes aprendem noções éticas e morais somente na escola, por meio, principalmente, da atuação dos professores. Dessa forma, além dos conhecimentos acumulados pela humanidade, os professores passam a ser um dos poucos referenciais que podem oferecer uma expectativa instrutiva para os estudantes. Esse fato aumenta a responsabilidade social do magistério e a importância de uma boa atuação. Afinal

Em um momento de crise de valores e de ausência de horizontes estimulantes, quando a indefinição cultural, a impotência diante de muitas decisões políticas condicionadas por interesses distantes da necessidade da maioria, a mercantilização e a fragmentação da cultura, os princípios de egoísmo, consumismo, competitividade e superficialidade se fazem presentes, a educação tem a tarefa de promover uma cultura de solidariedade, justiça, participação, respeito para com o demais e para com as diferenças, e a defesa dos mais fracos. Uma educação que estimule as pessoas a assumir a responsabilidade para com os demais de forma cotidiana, em sua vida familiar, profissional, cultural e associativa; capazes de agir e pensar, de forma sistemática, contra a corrente de uma cultura 
dominante, contraditória e submetida aos interesses de uma minoria (ZABALLA, ARNAU, 2010, p. 79).

Nesse viés, ensinar o aluno a ser competente no uso da escrita é uma maneira de auxiliar na sua promoção social e, consequentemente, a transformar a sua realidade. Com o passar dos anos escolares, o estudante adquire uma relativa autonomia e passa a utilizar a escrita em outros ambientes, como as redes sociais que oportunizam uma oportunidade dele expor suas opiniões, sentimentos e emoções, de forma diferente daquela que é solicitada na escola. A escrita, nesses ambiente, é espontânea; na escola, é controlada. Esse fato é algo novo no ambiente educacional. Como toda novidade, ainda gera polêmica sobre os seus efeitos no processo de aprendizagem. Entendemos essa nova dinâmica como algo favorável e irreversível e os professores podem fazer uso dessas novas tecnologias e dessa propensão natural do estudante em lidar com a escrita fora do ambiente escolar como incentivo ao trabalho de produção de textos. Garcez $(2012$, p. 8) afirma que "toda escrita pertence a uma prática social. Não se escreve por escrever. A escrita tem um sentido e uma função". Utilizar essa naturalidade com a qual o aluno encara a nova forma de escrever e tentar transpô-la para a prática escolar pode ser uma alternativa viável para incentivar o estudante a escrever melhor. $\mathrm{O}$ jovem precisa ver um sentido naquilo que escreve. Por isso as práticas de produção textual precisam ser significativas para que que o aprendiz sinta-se estimulado em escrever. Assim

A produção de textos é um forma de organização do pensamento e do universo interior da pessoa. A escrita não é apenas uma oportunidade para que a pessoa mostre, comunique o que sabe, mas também para que descubra o que é, o que pensa, o que quer, em que acredita. (GARCEZ, 2012, p.8).

Um estudante precisa ser orientado no seu processo de escrita, na descoberta das suas possibilidades e potenciais. Essa construção de possibilidades pode estar no cotidiano de todos os alunos e dos professores. O trabalho docente é relevante e, por isso, precisa estar em contínua evolução e em sintonia com as necessidades dos estudantes.

No tocante ao ensino da escrita, compreendemos que o trabalho com os gêneros do discurso podem ser uma alternativa eficiente para a promoção do conhecimento dos estudantes, uma vez que todas as atividades escolares são mediadas pela linguagem. A questão dos gêneros discursivos não é algo recente, contudo a efetivação de sua prática, nos ambientes escolares, ainda precisa ser melhor explorada, afinal

Todos os diversos campos da atividade humana estão ligados ao uso da linguagem. Compreende-se perfeitamente que o caráter e as formas desse uso sejam tão multiformes quanto os campos da atividade humana, o que, é claro, não contradiz a unidade racional de uma língua. O emprego da língua efetua-se em forma de enunciados (orais e escritos) concretos e únicos, proferidos pelos integrantes desse ou daquele campo da atividade humana. Esses enunciados refletem as condições específicas e as finalidades de cada referido campo não só por seu conteúdo (temático) e pelo estilo da linguagem, ou seja, pela seleção dos recursos lexicais, fraseológicos e gramaticais da língua mas, acima de tudo, por sua construção composicional. Todos esses três elementos - o conteúdo temático, o estilo, a construção composicional - estão indissoluvelmente ligados no todo do enunciado e são igualmente determinados pelas especificidade de um determinado campo da comunicação. Evidentemente, cada enunciado particular é individual, mas cada campo de utilização da língua elabora seus tipos relativamente estáveis de enunciados, os quais denominamos gêneros do discurso (BAKHTIN, 
2015, p.261-262, grifos do autor).

No questão da linguagem, todos os estudantes, antes mesmo de iniciarem a sua vida escolar, já estão familiarizados com determinados gêneros, pois os "gêneros do discurso nos são dados quase da mesma forma que nos é dada a língua materna a qual dominamos livremente até começarmos o estudo da gramática" (BAKHTIN, 2003, p. 282). De modo que o início do processo de ensino se baseia naquilo que o estudante já conhece. A partir desse diagnóstico inicial podemos apresentar novas possibilidades de trabalho que tenham concretude para o aluno pois "qualquer que seja o aspecto da expressão-enunciação considerado, ele será determinado pelas condições reais da enunciação, isto é, antes de tudo pela situação social mais imediata" (BAKHTIN/VOLOCHINOV, 2010, p. 116, grifos dos autores). Ou seja, o ambiente em que vive o estudante influencia diretamente na forma como ele se manifesta e, como professores, podemos tornar o ensino significativo para que os estudantes sintam-se como partes integrantes da processo escolar e consigam uma interação efetiva com os colegas, professores e com o conhecimento organizado. Sobre a questão da interação, Bakhtin/Volochinov afirmam que

A verdadeira substância da língua não é constituído por um sistema abstrato de formas linguísticas nem pela enunciação monológica isolada, nem pelo ato psicofisiológico de sua produção, mas pelo fenômeno social da interação verbal, realizada através da enunciação ou das enunciações. A interação verbal constitui assim a realidade fundamental da língua (BAKHTIN/VOLOCHINOV, 2010, p. 127, grifos dos autores).

Essa interação pode ser ensinada para que os estudantes consigam colocá-la em prática por meio dos seus escritos a fim de superar as produções textuais permeadas de artificialidades. A escola é o espaço social determinante no qual o aluno, enquanto sujeito social incipiente, pode encontrar apoio pedagógico e material para se integrar de forma completa e independente em todos os outros lugares. Pode aprender a refletir sobre os diferentes aspectos (políticos, econômicos, éticos) da sociedade e a partir disso emitir as suas próprias opiniões, fazer apontamentos e pensar em ações efetivas para contribuir e transformar a sua realidade mais imediata.

Geraldi (2015, p. 98) aponta que existem condições para que uma escrita significativa aconteça. Um sujeito somente escreve efetivamente quando tem o que dizer para alguém que sabe que lerá e terá, com esse escrito, alguma interação expressiva e que estabeleça um novo sentido para essa atividade. Com relação à produção de textos na escola, o autor também afirma que

O professor somente ensina a escrever se assume os processos de escrever do aluno, tornando-se dele um co-enunciador, um leitor privilegiado e atento, um colaborador capaz de encorajar o outro a continuar buscando a melhor forma de dizer o que quer dizer para quem está dizendo pelas razões que o levam a dizer o que diz (GERALDI, 2015, p.98-99).

Desta forma, o professor precisa estar envolvido diretamente no processo de produção do texto do aluno, auxiliando-o com ideias e novas proposições, a partir do que o aluno conseguiu expor. Assim, a participação docente vai muito além das orientações formais do campo da linguagem que são importantes também, mas não podem ser motivo de obstrução do processo criativo do aluno. Um aluno pode, apesar dos inúmeros desvios dos 
aspectos formais e textuais do texto, apresentar ideias interessantes e que precisam ser lapidadas e trabalhadas para formar um discurso efetivo. Se a mediação docente ficar focada em aspectos formais, corre-se o risco de perder o aluno para atividades protocolares. As refacções textuais, tantas quanto possíveis, precisam ser orientadas para que o aluno compreenda e assimile o processo de construção da sua escrita.

Essa ida e vinda dos textos entre o estudante e o professor possibilita que o aluno se torne responsivo, ou seja, ocupa, diante do texto/discurso apresentado uma posição para melhorá-lo, discordar dele, utilizá-lo, modificá-lo, entre outras opções (BAKHTIN, 2015, p. 272). Assim, de acordo com Bakhtin (2015, p. 273) “ toda compreensão plena real é ativamente responsiva" e essa responsividade potencializa os estudantes a se tornarem sujeitos do seu discurso, tomando posse das suas palavras e opiniões e não apenas reproduzindo o que outros escreveram ou disseram.

Para melhor ilustrar os pressupostos expostos, apresentamos, na sequência, um processo de produção de textos no Ensino Fundamental, construída a partir da realidade vivida pelos estudantes e com a participação da professora como co-autora no processo de produção dos textos.

\section{Relato de experiência}

A experiência que relataremos foi aplicada em uma turma de $7^{\circ}$ ano do Ensino Fundamental de um colégio do campo, localizado no interior do município de Marechal Cândido Rondon, Estado do Paraná. O município faz fronteira com o Paraguai, através do Lago de Itaipu ${ }^{1}$. Por conta dessa proximidade, muitas famílias que trabalham ou possuem terras no vizinho país, preferem que os filhos estudem no Brasil, de forma que esses estudantes residem com outros familiares nas comunidades próximas à escola.

A proposta foi escrever um texto de memórias sobre alguma experiência vivida pelos alunos e que tivesse um significado especial para cada sujeito. Antes, porém, de apresentar a proposta de produção textual, apresentamos um texto do mesmo gênero, denominado $D a$ escuridão para o colorido ${ }^{2}$ para ser trabalhado em sala de aula, para que os alunos compreendessem como deveriam encaminhar a sua própria produção.

O texto em questão foi finalista do gênero na Olímpiada de Língua Portuguesa do ano 2010 e sua escolha ocorreu pelo fato da autora ser aluna de escola pública e da mesma faixa etária dos alunos do $7^{\circ}$ ano. O trabalho consistiu de uma leitura individual e silenciosa. $\mathrm{Na}$ sequência, foi realizada uma leitura coletiva, durante a qual os alunos expuseram as dúvidas com relação ao significado de algumas palavras e de expressões ou situações relatadas no texto e que não fazem mais parte do cotidiano das pessoas. Ainda sobre o texto, elaboramos questões para os alunos responderem e refletirem sobre sua finalidade, linguagem e seu significado.

Apresentamos, ainda, um texto do mesmo gênero, elaborado pela professora, denominado No limiar da lembrança, ${ }^{3}$, com recordações da época da primeira escola. $\mathrm{O}$ objetivo foi mostrar que a docente também pode escrever sobre aquilo que solicita aos alunos

\footnotetext{
${ }^{1}$ O Lago de Itaipu foi formado em 1982 para possibilitar a geração de energia elétrica na Usina Hidrelétrica de Itaipu em Foz do Iguaçu-PR. Possui $180 \mathrm{Km}$ de extensão desde a cidade de Guaíra até Foz do Iguaçu. Sua formação aconteceu no leito do Rio Paraná, na divisa entre o Brasil e o Paraguai. O lago possibilita a navegação em toda a sua extensão, além de oportunizar a travessia entre os dois países por meio de pequenas embarcações. Algumas prestam serviços de transporte comercial de passageiros.

${ }^{2}$ Texto finalista da Olimpíada de Língua Portuguesa (2010), disponível em https://www.escrevendoofuturo.org.br/EscrevendoFuturo/.../20101201memorias.pdf, acesso em 03/11/2017.

${ }^{3}$ Texto de Memórias, de nossa autoria, produzido para exemplificar o gênero.
} 
e mostrar uma proximidade enquanto pessoa dotada de lembranças, sentimentos e emoções. $\mathrm{Ou}$ seja, tornar a relação professora-alunos mais próxima. Foi realizada a leitura e compreensão oral do texto e muitos estudantes, durante essa atividade, quiseram expor também as suas próprias lembranças sobre fatos abordados no texto, além de ficarem curiosos ao descobrir que a própria professora estudara em uma pequena escola rural de uma localidade próxima a deles.

Os aprendizes, estudantes do Ensino Fundamental, precisam ser orientados e esclarecidos sobre o que se espera deles em cada prática de produção. Vamos assim, ao encontro ao que diz Geraldi ao estabelecer que

Por mais ingênuo que possa parecer, para produzir um texto (em qualquer modalidade) é preciso que:

a) se tenha o que dizer;

b) se tenha uma razão para dizer o que se tem a dizer;

c) se tenha para quem dizer o que se tem a dizer;

d) o locutor se constitua como tal, enquanto sujeito que diz o que diz para quem diz (ou, na imagem wittgensteiniana, seja um jogador no jogo);

e) se escolham as estratégias para realizar (a), (b), (c) e (d). (GERALDI, 1997, p. 137).

$\mathrm{Na}$ proposta em questão, entendemos que os requisitos acima foram contemplados. Vejamos a sequência: a) precisa contar uma lembrança que o marcou; b) a razão é para cumprir uma obrigação escolar e ter o seu trabalho exposto; c) além da professora, suas memórias serão lidas pelos colegas e pela comunidade escolar; d) o aluno se constitui como sujeito da sua produção já que conta algo seu, caracterizando certa singularidade; e) enquanto estratégias salientamos: a apresentação preliminar de textos do mesmo gênero, a entrega de uma grade de correção com os itens a serem observados durante a escrita, que será explicitada na sequência; a exposição pública do texto; a escolha de uma imagem ilustrativa que dialogue com o discurso do aluno.

Por se tratar de alunos do Ensino Fundamental, entendemos que o professor é destinatário natural dos textos. Os estudantes compreendem isso, já que parte do trabalho do docente é orientar a produção e as refacções antes que a mesma chegue aos demais destinatários. A artificialidade que se pretende combater na elaboração dos textos escolares diz respeito às produções desprovidas de significado em que professores e alunos não se envolvem com o discurso e textos são produzidos apenas com função protocolar de se escrever algo ou qualquer coisa.

Esclarecemos que a produção foi encaminhada e, desde logo, os alunos foram informados que os trabalhos seriam expostos na Mostra de Trabalhos que o Colégio realiza a cada trimestre, no momento da entrega de boletins. Toda a comunidade escolar visita essa exposição e, dessa forma, tem acesso aos textos.

Além das condições de produção, compreendemos que o processo de produção escrita é uma prática social compartilhada. Por isso, sempre que possível, procuramos realizar a mesma proposta sugerida para os alunos, para, como já registrado acima, humanizar e aproximar o professor da realidade vivida pelos educandos. Ao pensar e escrever a proposta, o sujeito-professor o faz em função dos seus sujeitos-alunos e materializa a comunicação por meio da sua enunciação. Isso constitui, de acordo com Bakthin/Volochinov (2014, p. 127), a realidade fundamental da língua concretizada pela interação verbal efetiva. Os autores afirmam, ainda, que é na interação que reside a verdadeira substância da língua enquanto organismo vivo e que evolui historicamente. Dessa forma o estudo com a linguagem deve 
estar centrado nas condições concretas em que se realiza (BAKHTIN/VOLOCHINOV, 2014, p. 128-129).

Explicitadas as metodologias preliminares, no momento que antecedeu a produção dos alunos, foi entregue aos estudantes a seguinte grade de correção:

Tabela 1

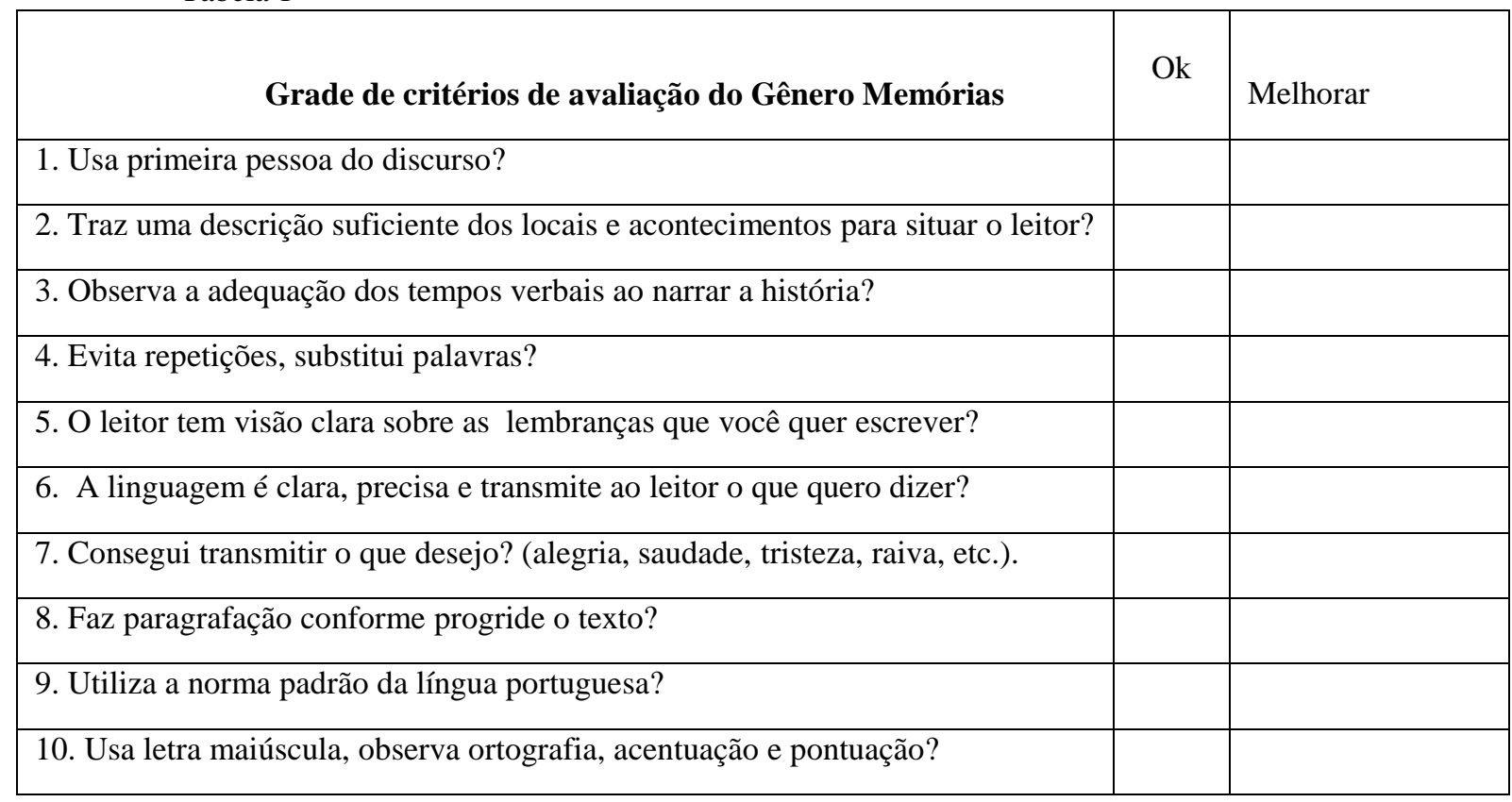

Fonte: elaborada pela autora.

Cada elemento da tabela foi lido e explicado para tentar garantir uma compreensão mínima dos elementos solicitados e tentar, antecipadamente, prever alguns desvios frequentes nas produções de estudantes. Explicada essa situação, os alunos produziram, na sala, os textos em que deveriam apresentar uma lembrança marcante. A análise dessas produções fará parte da próxima seção.

\section{Análise dos textos}

Como já informamos, a turma é do $7^{\circ}$ ano do Ensino Fundamental, com problemas de aprendizagem e disciplina, composta por 14 meninos e 3 meninas. Deste total, dois são diagnosticados com laudo de déficit de atenção e indicação de avaliações personalizadas e diferenciadas. Dos textos produzidos, selecionamos quatro para análise e que serão transcritos na sequência, conforme a versão original. Informamos que se trata-se da primeira escrita da proposta.

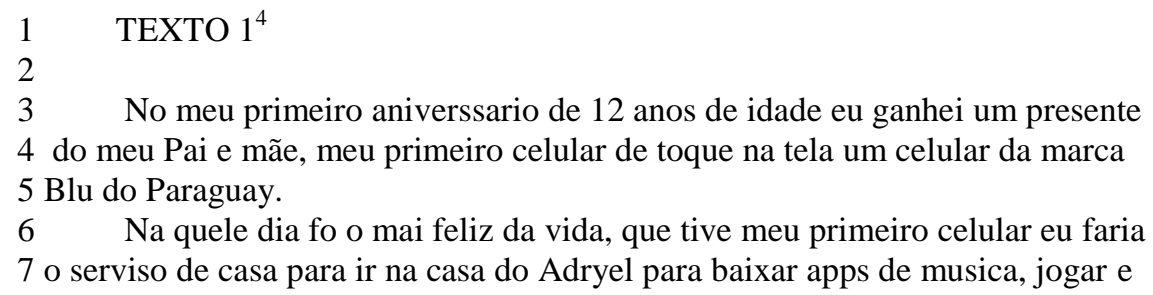

\footnotetext{
${ }^{4}$ Os textos dos alunos, transcritos conforme a versão original, estão citados em letra 10 e sem alinhamento de parágrafo à direita.
} 


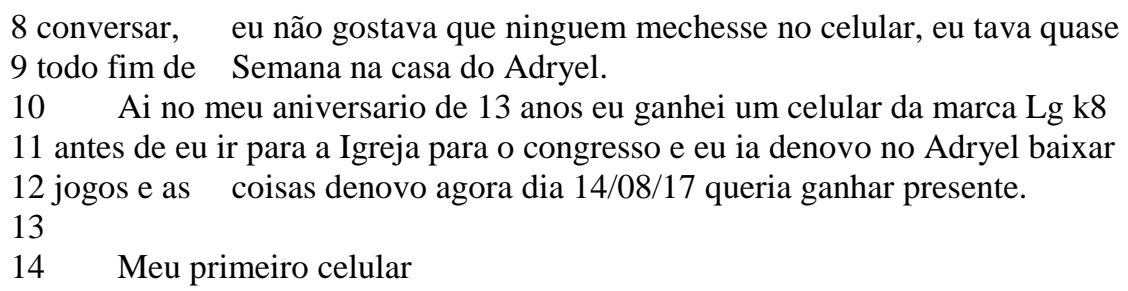

Neste primeiro texto, percebemos que o aluno procurou relatar uma memória importante para ele que foi receber um celular com tela sensível ao toque. Algo aparentemente corriqueiro na vida de adolescente. Contudo, o aluno em questão é oriundo de uma família humilde e receber esse presente foi, de fato, relevante para ele que não tem acesso à internet e precisou ir até a casa de um colega para se conectar.

Com relação aos aspectos formais, percebemos que aluno comete algumas transgressões como a hiper e a hipossegmentação (linhas 6,11 e 12) e a supressão e troca de fonemas nos finais das sílabas (linhas 4, 5 e 6). Além desses, observamos a troca de letras pela violação das regras invariantes que regem alguns sons (linhas 3 e 8). A produção escrita do aluno beira os limites do sistema de organização oral e podemos observar, ainda, problemas de concordância verbal e pontuação.

No tocante aos aspectos textuais, podemos dizer que o texto possui uma relativa informatividade. $\mathrm{O}$ assunto é abordado superficialmente o que prejudica a progressão e a continuidade do mesmo. O aluno não conseguiu manifestar toda a euforia que sentiu em receber tal presente. Nesse caso, sabia o que queria dizer, o problema está no como disse. Poderia ter uma articulação diferente para favorecer a compreensão semântica por meio da utilização de descrições mais minuciosas e adjetivos que caracterizassem com mais efetividade essa lembrança. Com relação aos elementos coesivos, o autor repete pronomes e substantivos o que prejudica a construção dos significados do discurso. O título, outro aspecto importante, foi colocado por último. Entendemos que é adequado ao discurso do aluno, porém não é expressivo.

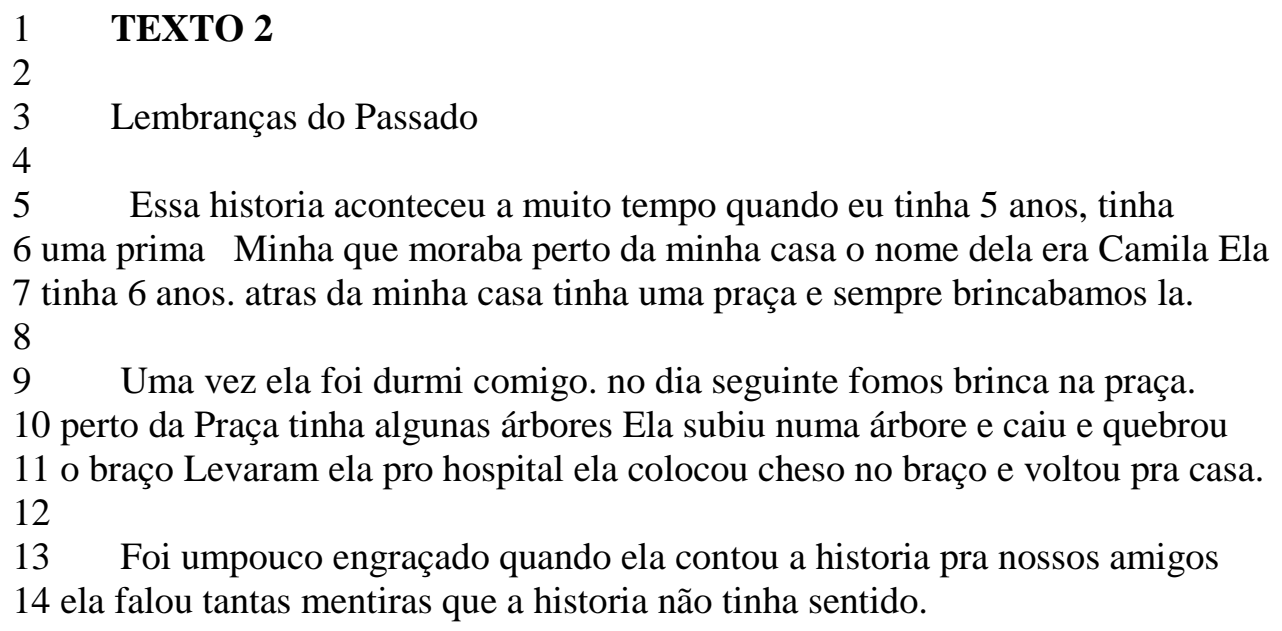

O segundo texto foi produzido por uma aluna oriunda do Paraguai, filha de brasiguaios e que estudou no país vizinho. Essa informação é relevante e precisa ser considerada ao analisar as trocas entre os fonemas $/ \mathrm{b} / \mathrm{e} / \mathrm{v} /$ ao considerarmos que ela está no processo de transição entre as línguas espanhola e portuguesa. Acreditamos que esse processo influenciou, também, a maneira como ela grafou a palavra gesso na linha 11. 
Uma análise dos aspectos textuais aponta que falta informatividade no texto da aluna. Ela quis dizer, mas não o fez, que essa lembrança é de um episódio acontecido no Paraguai. Essa omissão prejudicou a progressão e continuidade do texto para sua plena compreensão. Por sua vez, há repetição de pronomes e substantivos o que comprometeu a fluidez. O título é redundante, pois lembrança já remete ao passado.

Dentre os aspectos formais analisados destacamos a supressão de fonemas no final das palavras (linha 9); também neste quesito ocorre a omissão do $h$ na linha cinco. Na linha treze apresenta um caso de hipossegmentação e, ao longo do texto, problemas com pontuação e acentuação. Além disso, a aluna deixou linhas em branco no intervalo entre os parágrafos.

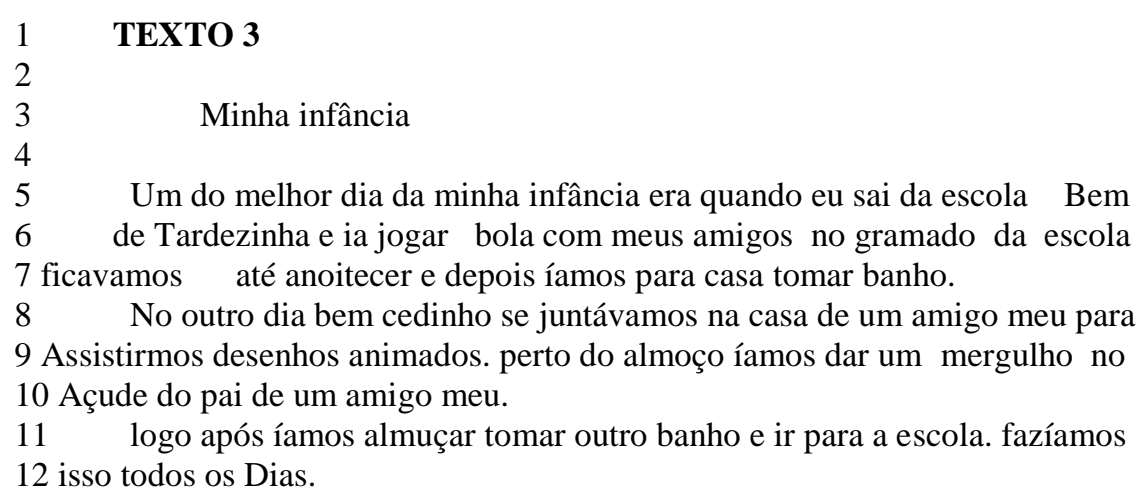

O texto acima foi produzido por um aluno com dificuldades de estabelecer uma compreensão adequada a sua produção. O estudante ainda não dominou as noções básicas como o uso de maiúsculas após o ponto. Aleatoriamente, no meio do período, grafa uma palavra com letra maiúscula. Utiliza o pronome oblíquo de maneira incorreta (linha 8) e apresenta o alteamento de vogal na linha 11. A produção carece, ainda, de pontuação, acentuação e adequação do uso de alguns verbos e concordância nominal.

O texto está muito próximo da oralidade, por isso a quinta linha se apresenta truncada o que prejudica uma articulação adequada das ideias. Num texto curto o estudante trouxe diferentes lembranças que remetem a sua não tão distante infância. Não faz, entretanto, um aprofundamento na descrição dos fatos, na caracterização de seus sentimentos o que resulta em prejuízos para a informatividade e, consequentemente, para a progressão e continuidade dos fatos que poderiam ter sido melhor explorados. $\mathrm{O}$ título está adequado ao que o estudante tentou demonstrar: recortes da sua infância, sem, contudo, ser expressivo e estimulante.

\section{TEXTO 4}

2 3

4

5 Uma fez a três anos eu fui morar para o Paraguai, na esperança de saber 6 a lingua Espanhola e saber como é a escola lá no paraguai.

$7 \quad$ Então descobri é muito mais diviseu no paraguai do que aqui no Brasil 8 o que eu aprendi na $5^{\mathrm{a}}$ sere e na $6^{\mathrm{a}}$ sere eu to aprendendo na $7^{\mathrm{a}}$ sere aqui no 9 Brasil.

10 Uma coisa que eu achei engrazada era o nome da minha escola lá do 11 Paraguai, o nome era Escuela Basica Amistad e eu não sabia o que significafa 12 a palavra a Amistad depois que eu descobri que era Amizade.

13 O mais difísil era falar com as professoras em espanhol. eu não entendia 14 nada, iso era divisil mais eu tinha Amigos que estudavam junto comigo e 
15 falavam em Portuques ainda bem por que eu iria tar reprovado se não fose o

16 Tiago, Flavia, Adinei e a Natalia.

O quarto texto está praticamente inserido no sistema de organização oral. Palavras como difiseu do título, sere (linha 8) e tar na linha 15 correspondem à fala do estudante. A palavra difícil é grafada de três maneiras distintas ao longo da produção, como percebemos nas linhas 3, 7, 13 e 14. A lembrança do aluno girou em torno do fato da língua espanhola ser difícil para aprender para quem não a conhece e o fato, consequente, da escola no Paraguai parecer, na visão do estudante, ser mais avançada do que no Brasil, uma vez que ele não compreendia as professoras devido às barreiras do idioma. Fora a menção da comunicação por mímica não trouxe, contudo, nenhum exemplo que ilustrasse de maneira mais enfática essa dificuldade por ele relatada. Assim, comprometeu a informatividade, progressão e continuidade do texto. Repete pronomes e substantivos o que prejudicou a fluidez do texto.

Apresenta trocas dos fonemas /v/ e /f/, problemas com a utilização das maiúsculas e outras trocas de letras por violação das regras que representam os sons. Essa troca, em parte, pode ser justificada pelo trânsito do estudante entre os dois países. Questões familiares o levam a morar com avó no Brasil e com outros parentes no Paraguai.

Como já mencionamos, os alunos sabiam o que precisavam escrever. Conheciam os objetivos e tinham noção de quem seriam os destinatários. O problema está centrado no como escrever. Cada aluno expôs uma vivência sua, estava envolvido como sujeito no processo. Nos textos em questão, os alunos ainda não dominam os recursos da língua. Contudo o conhecimento desses mecanismos, por si só, não garante o acesso à escrita. Riolfi (2014, p. 122) afirma que esse acesso depende de "lento aprendizado de cumplicidade com as palavras". Aprender a escrever é um processo que requer reflexão, trabalho, conhecimento do que se quer e novas escritas a partir do que foi inicialmente produzido.

Para tanto, é necessário não só que nos ensinem quais recursos da língua podemos usar, mas também quais as razões e os significados de escrever. A entrada no mundo da escrita não se limita e não se realiza somente pelo ato de ser alfabetizado. Ela requer e constrói, ao mesmo tempo, um domínio simbólico e reflexivo da linguagem (RIOLFI, 2014, p. 122).

A partir dessa afirmação inferimos que, além de aprender os recursos da língua, o aluno precisa ser orientado a utilizar a linguagem escrita de maneira que ele se constitua por meio dela. Aprenda a se manifestar, expor sua opinião, seus sentimentos, suas frustações.

As produções acima analisadas são o ponto de partida para o estudante e, principalmente, para o professor que pode verificar os aspectos positivos e os pontos que precisam de intervenção. A produção não pode ficar restrita a uma função protocolar do aluno preencher palavras em um papel e entregar ao professor para cumprir sua obrigação. É importante que ele compreenda todos os passos desse processo. Entenda o processo como trabalho, reflexão e estudo que gera conhecimento. Assim, apresentaremos na sequência algumas proposições de intervenção pedagógica a partir dos problemas apontados.

\section{Proposições metodológicas e resultados}

Apresentados os textos e realizada a análise das dificuldades dos alunos torna-se necessário uma intervenção pedagógica no sentido de re(orientar) o processo de aprendizagem dos alunos que são sujeitos em construção. Os estudantes em questão, inseridos num ambiente 
familiar com pouca ou nenhuma possibilidade de leitura, encontram na escola e, principalmente, no professor, o principal agente de mudanças de suas situações.

O docente precisa dedicar tempo para a análise dessas produções, a fim de formular diagnósticos e propor atividades que resultem na melhoria da qualidade dos textos. De modo que

O professor precisa, como profissional da educação, criar dispositivos com fundamentação teórica para que consiga vislumbrar, para além das aparências, a assimilação, as falhas, os pontos que precisam de reforço, etc. Ele saberá transformar suas experiências em meio eficiente de diagnóstico linguístico que norteará as estratégias de ação para um bom trabalho. Isso não quer dizer que vamos trabalhar com um aluno ideal, sem problemas de aprendizagem, de sociabilidade ou familiares. Ao contrário, nosso ideal é que a docência se realize em um espaço real, onde esses conflitos existem e sempre existirão. (RIOLFI, 2014, p. 15).

Para conseguir transformar suas experiências e escolher estratégias exitosas com alunos reais é preciso que o professor conheça a turma com a qual trabalha. Isso facilita muito a percepção e a forma de agir. Sabemos que nem sempre é possível devido a forma como o sistema de educação funciona. Contudo, o professor precisa ter consciência que ele é o responsável pela condução dos trabalhos da sala e pela articulação dos conhecimentos.

A turma da qual selecionamos os textos não é muito numerosa. Porém, são alunos que possuem uma relação conflituosa entre os colegas que se reflete por meio de atitudes agressivas, palavrões e xingamentos. É uma típica turma considerada problema na escola. Porém, apesar das dificuldades existentes, acreditamos que por meio de um trabalho sério com a escrita que valorize as singularidades de cada aluno transformando-os em sujeitos principais do processo de aprendizagem, boa parte dos problemas disciplinares é resolvida.

Desta forma, a primeira proposta de intervenção pedagógica que pontuamos foi a reescrita dos textos. Como mencionado no relato de experiências, foi entregue a cada estudante uma grade de correção para que fossem seguidas algumas orientações durante a produção. No verso dessa grade, no primeiro processo de correção, foram escritas algumas orientações no sentido de contribuir para o aluno melhorar a sua produção especialmente na questão da informatividade. Foram realizadas, ainda, marcações no corpo do texto, como sublinhar palavras grafadas de forma incorreta. Por ocasião da reescrita foram entregues dicionários para os alunos procurarem o motivo daquelas palavras estarem assinaladas nos seus manuscritos.

O aluno, ao escrever o seu texto, agiu de forma ativa perante um comando de produção proposto pela professora. Esta, por sua vez, ao agir sobre o texto no processo de correção, revisou o texto do aluno, comentou, elogiou, sugeriu alterações, tornando-se, assim, coprodutora do texto através da sua mediação. No processo de reescrita essa troca de informações continua uma vez que os estudantes podem responder as apontamentos, aceitálos, rejeitá-los e, inclusive, rejeitá-los. O importante é que desse processo resulta uma interação dialógica que proporciona modificações no produto em questão que é o discurso produzido. Nesse processo de ir do aluno para a professora se constitui uma relação dialógica caracterizada pela responsividade. Sobre isso, Bakhtin (2015, p. 271) afirma que essas relações responsivas se constroem quando os interlocutores - aqui alunos e professora compreendem o significado do discurso, concordam com ele, discordam (total ou parcialmente) complementam-no e aplicam-no.

Menegassi (2013) afirma que a produção textual escrita envolve relações sociais que correspondem ao dialogismo vivo da língua. Na sala estão presentes sujeitos, valores e 
ideologias que transitam entre situações enunciativas de ensino e aprendizagem, "em que a responsividade é elemento constante e essencial para a aquisição de um saber." (MENEGASSI, 2013, p. 220).

Desse modo, o processo de reescrita dos textos foi uma alternativa viável e que possibilitou ao estudante revisitar o seu discurso e adequá-lo a partir de novas elaborações mentais e das orientações pedagógicas.

Outra proposição metodológica diz respeito aos aspectos formais da linguagem como os desvios ortográficos, a acentuação e pontuação a hiper e a hipossegmentação. É importante salientar que na turma em questão, com famílias carentes e sem acesso a bons materiais de leitura, somente na escola os estudantes têm acesso a bons materiais, textos e livros. Morais (2009, p. 70) mostra que a leitura de materiais impressos é uma fonte importante para a reflexão ortográfica. Os alunos da classe popular precisam ter, ao menos na escola, a chance de conviver com textos escritos que sigam as normas, com bons modelos de escrita correta sobre as quais possam construir suas reflexões. Assim, "É se defrontando com as formas corretas que o aluno poderá contrastá-las com suas hipóteses (sobre como se escreve esta ou aquela palavra) e descobrir se há ou não regras por trás do uso de tal ou qual letra" (MORAIS, 2009, p. 70).

Essa construção de hipóteses também é um processo com tempos variados entre os alunos. Os estudantes, então, precisam ser apresentados a bons modelos textuais para que percebam e reflitam sobre a sua própria escrita. Desta forma uma atividade de sala pode envolver a escolha de um dos textos com os problemas apontados (como na análise) e entregue aos alunos para que reflitam sobre e percebam o que precisa ser corrigido e melhorado. Naturalmente, que precisa ser feito com cuidado para não identificar o aluno a fim de evitar constrangimentos. Porém é uma atividade significativa já que parte da realidade em que eles estão inseridos. Não é um exercício artificial criado para sanar alguma dificuldade.

Importante também salientar a importância da leitura que precisa permear todo o processo de ensino-aprendizagem. É comum, nesta turma, os alunos afirmarem que não gostam de ler. Então diferentes estratégias precisam ser articuladas durante as aulas e nos momentos específicos de leitura como: gibis, revistas com assuntos interessantes e pertinentes à faixa etária e pequenas poesias que podem ser exploradas e ressignificadas para cada um dos alunos.

Sobre a escrita, um ponto relevante a considerar sobre a mediação pedagógica no processo de ensino, consiste numa mudança dos procedimentos pedagógicos tradicionais. $\mathrm{O}$ professor ao trabalhar junto com o aluno na sua produção consegue mais do que analisar os deslizes dos estudantes na articulação de ideias ou em desvios ortográficos. Consegue compreender a dificuldade que o processo de aquisição da escrita representa para os aprendizes. A esse respeito Geraldi (2015) sustenta que

Escrever não é uma tarefa fácil e certamente o fazer juntos é um caminho que permite construir a autonomia de ambos: do aluno e do professor, que também ele é chamado a escrever seus próprios textos, deixando de ser somente um agente de conservação da herança cultural disponível para se fazer também ele produtor de nova herança cultural, deixando nesta as marcas de seu tempo e de sua história (GERALDI, 2015, p. 182).

Esse fazer juntos representa uma possibilidade de mudança na maneira como os estudantes compreendem a escrita, com isso colaboramos na promoção do seu conhecimento e da sua capacidade transformadora. Acreditamos que essa parceria entre o professor e o aluno estabeleça uma relação cooperativa em todas as atividades escolares que forem propostas para os estudantes. 
Com relação à produção escrita analisada neste trabalho, apresentamos, em seguida, o resultado final que foi exposto para a comunidade escolar. A análise, anteriormente apresentada, foi elaborada com a primeira versão escrita pelos estudantes. O processo de produção, no entanto, teve três reescritas por parte dos alunos. Em cada uma dessas etapas as produções eram corrigidas e novas orientações anotadas e sugeridas para os estudantes.

Texto 1

Meu primeiro celular

No meu aniversário de 12 anos ganhei um presente do meu pai e da minha mãe: meu primeiro celular de toque na tela, da marca Blu.

Aquele dia foi muito legal! Eu tinha o meu celular. Depois que eu ajudei meus pais nos afazeres domésticos fui na casa do Adryel para baixar aplicativos de música gospel e jogos como o Clash Royale, Traffic Racer e, ainda, alguns aplicativos de conversa.

Eu não gostava muito que mexessem no meu telefone. Era só meu. Todos os finais de semana eu e o Adryel nos reuníamos para ficar batalhando nos jogos do celular.

No meu aniversário de 13 anos, ganhei outro celular. Fiquei muito empolgado com o presente porque iria viajar para um congresso da Igreja. Novamente fui até a casa do meu amigo para instalar novos aplicativos e jogos diferentes.

Sempre espero receber presentes. É super emocionante.

Texto 2

Lembranças

Há muito tempo, quando eu tinha cinco anos, morava no Paraguai, numa cidade chamada Caaguazu. Perto da minha casa morava Camila, minha prima de seis anos.

Atrás da minha casa existia uma praça com muitas árvores e vários brinquedos: escorregador, balanço, gangorra e vários outros. Sempre brincávamos lá.

Um dia, pela manhã, eu e Camila fomos brincar na praça. Ela subiu numa árvore, caiu e quebrou o braço. Fiquei muito assustada e saí correndo para chamar as nossas mães enquanto minha prima chorava desesperada de dor.

Camila foi levada para o hospital, onde recebeu atendimento médico, engessou o braço e voltou para casa.

Passado o susto, a história ficou engraçada com a versão contada por Camila. Ela disse que tinha subido na árvore por causa de uns cachorros que queriam atacá-la. Devido a uma pisada em falso ela caiu e os cachorros morderam o seu braço. Assim, essa história ficou meio engraçada e mal contada.

Texto 3

Minha Infância

Uma das melhores lembranças da minha infância é a dos finais de tarde, depois que as aulas terminavam. Todos dos dias, eu e meus amigos, jogávamos bola no campo que ficava ao lado da escola. Era pequeno, porém a grama era macia, amortecia nossas quedas e não machucava os nossos pés.

Após o jogo, íamos tomar banho no açude de um amigo nosso. A água era suja e tinha bastante lodo. Nós fazíamos guerrinha de barro até anoitecer. Sujo e cansado eu voltava para casa e escutava minha mãe reclamar da sujeira e me mandar para o banho.

Pelas manhãs eu e os outros meninos assistíamos desenhos animados na televisão, na casa de um deles. Perto do almoço, novamente, brincávamos no açude. Adorava aquela água barrenta e as brincadeiras que ela possibilitava.

Perto da hora do almoço, eu voltava para casa, tomava banho, almoçava e me dirigia para a escola. No final da tarde, recomeçava todo o ciclo de brincadeiras. Uma época feliz, com excelentes lembranças.

Texto 4

O tal do espanhol é difícil

Uma vez, há três anos, fui morar com uma tia no Paraguai, país que faz fronteira com a região em que moro hoje. Minha maior esperança era aprender a língua espanhola e conhecer o sistema escolar daquele lugar.

Descobri que é muito mais difícil estudar no Paraguai do que aqui no Brasil. Penso que as coisas estou aprendendo agora no $7^{\circ}$ ano eu já aprendi na $5^{\mathrm{a}}$ e $6^{\mathrm{a}}$ séries lá no outro país.

Uma coisa que estranhei muito nos primeiros tempos de Paraguai foi o nome da minha escola: Amistad. Só depois descobri que significava amizade. 
O mais difícil daquele tempo era falar com as professoras em espanhol. Eu não entendia nada. Até me comunicava com elas por meio de mímicas. A minha sorte foi ter amigos que me ajudaram na compreensão dos conteúdos que eu precisava.

Nessa versão final foi inserida uma ilustração escolhida pelos alunos e que tinha relação com o texto. O efeito estético ficou bem interessante e chamou atenção das pessoas que se dispuseram a ler as produções, durante a exposição dos textos para a comunidade escolar.

Numa comparação com a primeira escrita, podemos observar que os textos melhoraram consideravelmente. Naturalmente, alguns aspectos poderiam ter sido aprofundados e melhor caracterizados. Porém, como já abordamos, a escrita é um processo e o professor consegue perceber quando encerrar uma etapa de produção e sugerir outra, com novos desafios para os alunos. Assim, o papel principal é o do professor. Mediar o acesso do aluno ao conhecimento por meio da escrita é uma árdua e relevante tarefa. Podemos, por meio do nosso trabalho, fazer a diferença na vida de meninos e meninas que passam pelos bancos escolares e que têm, na escola, um dos poucos lugares para lidar com o conhecimento organizado. Em uma sociedade como a nossa, desestabilizada por questões éticas, econômicas e políticas a escola precisa ser um centro capaz de auxiliar o aluno a se tornar um sujeito histórico com possibilidade de modificar a sua realidade e agir sobre o curso de todos os processos sociais.

\section{Considerações finais}

No processo de ensino-aprendizagem o professor é o principal agente do trabalho e precisa guiar os estudantes para que estabeleçam as relações necessárias com a escrita e superem suas dificuldades. Um caminho para isso é facilitar o trabalho e apresentar o texto escrito em contextos funcionais, de modo que os estudantes percebam a importância da escrita e sua correta apropriação.

Neste trabalho, propusemo-nos a apresentar algumas considerações sobre a importância da produção textual como atividade interativa e o professor como colaborador efetivo dos estudantes no processo de produção textual. Apresentamos, um relato de experiência de produção textual, com a descrição dos procedimentos pedagógicos que antecederam a escrita dos estudantes.

Em seguida, realizamos uma seleção da primeira produção dos estudantes e separamos quatro textos para realizar uma análise dos elementos textuais e formais da escrita. Efetuados os apontamentos, apresentamos propostas de intervenção pedagógica para auxiliar os estudantes na reescrita e na compreensão dos elementos formais da linguagem para além dos textos

Essa proposição pode ser adaptada para qualquer turma do ensino básico. Outras possibilidades de intervenção podem ocorrer. A compreensão da produção textual como um processo colaborativo, de mediação, entre alunos e professores é uma discussão que deveria permear as formações pedagógicas. Temos a clareza de que as atividades propostas representam uma das alternativas possíveis de trabalho. Um ponto de partida para a reflexão e o trabalho significativo sobre o ensino da escrita na escola.

\section{Referências}


BAKHTIN, Mikhail. Estética da Criação Verbal. 6. Ed. São Paulo: Martins Fontes, 2015.

BAKHTIN, Mikhail; VOLOCHINOV, V.N. Marxismo e Filosofia da Linguagem. 16. ed. São Paulo: Hucitec, 2014.

GARCEZ, Lucília H. Carmo. Técnicas de Redação: o que é preciso saber para bem escrever. São Paulo: Martins Fontes, 2012.

GERALDI, João Wanderley. A aula como acontecimento. São Carlos: Pedro e João editores, 2015.

GERALDI, João Wanderley. Portos de Passagem. São Paulo: Martins Fontes, 1997.

MARCUSCHI, Luiz Antonio. Produção textual, análise de gêneros e compreensão. São Paulo: Parábola Editorial, 2008.

MENEGASSI, José Renilson; MOTERANI, Natalia Gonçalves. Aspectos linguísticodiscursivos na revisão textual-interativa. Trabalho Linguística Aplicada. Campinas, n(52.2): 217-227, jul./dez. 2013.

MORAIS, Artur Gomes de. Ortografia: ensinar e aprender. São Paulo: Ática, 2009.

NEVES et al. Ler e escrever: compromisso de todas as áreas. Porto Alegre: Editora da UFRGS, 2011.

RIOLFI, Claudia et al. In: CARVALHO, Anna Maria Pessoa (Coord.). Ensino de Língua Portuguesa. São Paulo: Cengage Learning, 2014.

ROJO, Roxane H. Rodrigues. Letramento e capacidade de leitura para a cidadania. In: FREITAS, Maria Tereza de A.; COSTA, Sérgio Roberto (Org.). Leitura e escrita na formação de professores. Juiz de Fora, MG: Universidade Federal de Juiz de Fora, 2002, p. $1-8$.

SOARES, Magda. Letramento: um tema em três gêneros. Belo Horizonte: Autêntica, 1998.

ZABALA, Antoni. ARNAU, Laia. Como ensinar e aprender competências. Porto Alegre: 
Artmed, 2010. 